\title{
Social networks and their impact on access to health care: insights from older widows living alone in Kottayam, South India
}

\author{
Mathew Sunil George ${ }^{1 \star}$ (D), Rakhal Gaitonde ${ }^{2}$, Rachel Davey ${ }^{1}$, Vyas Sukumaran ${ }^{3}$, \\ Itismita Mohanty ${ }^{1}$ and Penney Upton ${ }^{1}$ \\ ${ }^{1}$ Health Research Institute, University of Canberra, Canberra, Australia, ${ }^{2}$ Achuta Menon Centre for Health \\ Sciences, Sri Chitra Tirunal Institute of Medical Sciences and Technology, Kerala, India and ${ }^{3}$ National \\ Health Mission, District Hospital, Kottayam, Kerala, India \\ *Corresponding author. Email: sunil.george@canberra.edu.au
}

(Accepted 22 June 2021; first published online 29 July 2021)

\begin{abstract}
The feminisation of ageing observed across the world is a significant challenge in many societies. Women's greater longevity is associated with the increased likelihood of agerelated disability and morbidity. Furthermore, gendered disadvantage and poverty can make access to health care increasingly problematic in later years. Among the Indian states, Kerala has the highest number of residents above the age of 60 and many are older widows. Given this context, this paper explores what promotes access to health care for older widows living alone in the south Indian state of Kerala. Thirty-two indepth interviews, eight focus group discussions and eight units of participant observation were carried out among widows, health-care providers and key informants. Applying a reflexive inductive approach to our analysis, the main barriers to access that emerged were altered family structures and loneliness, whilst enablers included good social networks and access to neighbourhood clinics. Our participants' social networks were drawn from three levels: family, neighbourhood and the wider community. The ability to form a personal community from their social networks and the quality of relationships within this community strongly predicted the capacity to access health care. Efforts to improve access to health care for older widows requires a response that is rooted in the socio-cultural context of the community. Comprehensive social protection policies that promote initiatives to engender social capital among the older population, decentralised primary health-care services, and the training and sensitisation of health service staff would be key to promote equitable access for older widows.
\end{abstract}

Keywords: ageing; widowhood; social networks; access; universal health coverage (UHC); Kerala; India

\section{Introduction}

An ageing population, driven by the decline in fertility and increased longevity due to reduced mortality and increased life expectancy, is a common demographic

(c) The Author(s), 2021. Published by Cambridge University Press. This is an Open Access article, distributed under the terms of the Creative Commons Attribution licence (http://creativecommons.org/licenses/by/4.0/), which permits unrestricted re-use, distribution, and reproduction in any medium, provided the original work is properly cited. 
factor across the world. Globally, the population of those who are 60 years and above has been rapidly increasing, with future growth projected to occur primarily in developing countries, including India (World Health Organization (WHO), 2007; United Nations, 2019). By 2050, the majority of older people are expected to be living in Asia (Barber and Rosenberg, 2017). Women usually outlive men, thus by 205054 per cent of the world's population aged 65 and above are expected to be female (United Nations, 2019). This 'feminisation of ageing' has been identified as a challenge to the health-care system (Davidson et al., 2011), since women tend to live longer than men and typically experience serious illness and suffer from co-morbidities as a consequence of living longer (Crawley, 2008; Byles et al., 2019). At the same time, older women often encounter unique challenges including fewer financial resources to draw on than their male counterparts, plus greater possibility of living alone and dismissal of their health issues as just a by-product of the ageing process (Hurst et al., 2013; Ní Léime et al., 2015; Song and Kong, 2015). Cultural constructs of gender shape not only how society perceives and responds to a woman's health (Tuohy and Cooney, 2019) but also how older women understand their own health or illness. Gender and ageing are widely accepted as responsible for exclusion and poor access to resources (Verbrugge, 1985; Vlassoff, 1994; WHO, 2005a; Taket et al., 2009), thus the feminisation of ageing means greater vulnerability for the increasing numbers of women living alone into very old age, including marginalisation of access to local health services and other existing support systems (DiGiacomo et al., 2013).

Multiple international agreements and frameworks affirm the rights of every individual irrespective of age or gender to attain the highest possible health and access to health-care services (WHO, 1978, 2005b). However, with regard to women's health, the focus is overwhelmingly on women of reproductive age. The health needs of older women, their rights and specific requirements tend to be forgotten (WHO, 2007; Davidson et al., 2011). For example, despite ensuring universal health coverage (UHC) as its central tenant, the WHO's 13th General Programme of Work uses outcome indicators that by definition exclude older women. Thus, measures of mortality due to non-communicable diseases (NCD) only include individuals up to the age of 70 , while the indicators for intimate partner violence, decision making with regard to sexual rights and use of contraception are limited to those aged 49 years and under (WHO, 2020). Such omission has the consequence of excluding many older people, particularly women, from these metrics. The implications of this are likely to be significant since if we do not assess health outcomes of a considerable section of the population, appropriate services will not be designed or provided for them.

In India, the older population is projected to increase from the current 8 per cent to 20 per cent by the year 2050 (United Nations, 2015). The Government of India defines all those who are 60 years and above as the older population (Acharya, 2018). According to the last census in India, the proportion of persons aged 60 years and above was 8.6 per cent of the total population (Registrar General \& Census Commissioner of India, 2011). While increased longevity in southern states of India is a primary driver of the increase in the proportion of the older population, other Indian states such as Haryana, Odisha, Himachal Pradesh, Punjab and Maharashtra are also experiencing an increase in their older populations (Alam and 
Karan, 2010). Among the Indian states, Kerala stands out, with the growth in the number of the older adults having increased over the past few decades (Registrar General of India, 2017). As against the national average of 8.3 per cent, 13.1 per cent of the total population in Kerala is over the age of 60 (Registrar General of India, 2017). Furthermore, among those aged 60 and above, women outnumber men and the majority of them are widows (State Planning Board, 2019). This is in contrast with other parts of India where men outnumber women among those above the age of 60 (Desai et al., 2010). It has been predicted that these trends will continue, thus around 20 per cent of the population in Kerala will be above the age of 60 by 2026 (State Planning Board, 2019). Four factors have driven this demographically unique nature of Kerala: the decline in fertility rates below replaceable levels, the cultural practice of men being older than women when they marry, the longer life expectancy of women over men (Desai et al., 2010) and the migration of the younger population as they seek better prospects outside the state (Kurian, 1979; Desai et al., 2010).

In addition to gender and ageing, the stigma of widowhood in traditional societies like India adds an additional layer of vulnerability which impacts not just on health-care access but also on other basic rights (Chen, 1998; Dreze, 1990). Cultural constructs of widowhood have an impact on what is considered socially acceptable as rights for widows. Several studies have pointed to worse health outcomes associated with being an older widow in India compared to their married counterparts (Sudha et al., 2006; Roy and Chaudhuri, 2008; Sreerupa and Rajan, 2010; Basu and King, 2013; Samanta et al., 2015). Previous work in India has shown that while morbidity and the resultant need for health care for older widows is high, the utilisation of health care is poor (Agrawal and Keshri, 2014; Perkins et al., 2016). Even in Kerala, which is known for its matrilineal traditions, widowhood has been shown to add to vulnerability, including exclusion from health care and restrictions on social mobility (Acharya, 2018). Marital status has been found to be associated with both health and health-care utilisation among older adults in other settings too (Visaria, 2001). Thus, in the context of health-care access in India, older widows form a particularly vulnerable population. This paper has two objectives: to explore the various factors that promoted or hindered older widows' access to health-care services in the south Indian state of Kerala and to present recommendations for both policy and practice that would result in better access to health care for older widows.

\section{Methods}

\section{Study setting}

Kottayam is one of the 14 districts of Kerala with a total population of $1,974,551$ (Registrar General of India, 2001). Data from the last census estimate around $1,409,158$ of the population are living in rural areas and around 140,397 in urban centres (Agrawal and Keshri, 2014). Kottayam is sub-divided into five taluks ${ }^{1}$ and 100 villages (District Administration Kottayam, 2020a). Provision of health care in India follows a mixed model with both public and private health-care providers existing side by side. The public health system follows a hierarchical structure of facilities that are based on population norms and starts with sub-centres that are 
the most peripheral health-care facilities followed by the Primary Health Centres (PHCs), Community Health Centres (CHCs), sub-district hospitals and district hospitals (Chokshi et al., 2016). At the top of this hierarchical structure are government medical colleges. The private health-care system consists of a wide variety of health-care facilities starting from standalone clinics managed by an individual medical professional right up to super-speciality hospitals. The public health system in Kottayam consists of 55 PHCs, 20 CHCs, three sub-district hospitals, four district hospitals and a Government Medical College (District Administration Kottayam, 2020b). Each PHC has sub-centres under its jurisdiction as per the population norms. ${ }^{2}$ In addition to public health facilities, the private health-care system comprises 13 hospitals providing facilities ranging from primary to superspecialist care as well as numerous individual clinics. According to the latest report by the state government, 15.9 per cent of the total population of Kottayam is above the age of 60 (State Planning Board, 2019).

\section{Data collection}

Ethnographic fieldwork was conducted between November 2018 and January 2019 and again between October 2019 and January 2020 in Kerala by the first author (MSG) who is fluent in the native language of the participants (Malayalam) and has prior experience working with marginalised communities. Prior to commencing data collection, MSG visited the health facilities in areas where there were a greater number of widows above 60 years who were living alone. During these visits, discussions were held with the medical officer of the health facility as well as the community health workers at the facility who are known as accredited social health activists (ASHAs). The purpose of the study was explained, along with details of what participation would involve for widows, health-care workers and key informants. The specific areas and details of widows who were living alone and the ASHA working in that area were also noted. During the first visit to the community, MSG was accompanied by the area ASHA. During this visit, initial contact was made with potential participants, the purpose of the study was explained, willingness to participate was ascertained, and a tentative time and date for a second visit for data collection was fixed. Any questions raised by potential participants were answered and contact details were obtained. In some instances, the initial visit was also utilised to introduce the researcher to the local representative of the area and explain the study and its purpose. This was deemed necessary, especially in rural areas, as communities were wary about outsiders visiting women who were living alone. This approach enabled participants to become familiar with the researcher, built rapport, and enabled a frank exploration of issues related to their health and health-care access.

In-depth interviews (IDIs) with the widows took place at their homes whereas IDIs and focus group discussions (FGDs) with health-care workers and key informants took place at their office, after their work hours or at their homes depending on their preference. One of the key informant interviews was conducted over the telephone. Participant observation (PO) involved being present at the PHCs and $\mathrm{CHCs}$ in their common areas during the designated day when the older men and women in the area were asked to come for check-ups and collect their 
medication, and accompanying the mobile neighbourhood clinic (vayomitram) team (Kerala Social Security Mission, 2018) in Vaikom taluk during their visits to the different wards. This enabled both observation and interaction with older men and women who visited the clinic as well as health-care providers who were present. The first author also carried out PO at Mahatma Gandhi National Rural Employment Guarantee Scheme ${ }^{3}$ (MNREGA) allotted worksites and observed the inclusion of older widows into communal work that was implemented.

\section{Sampling}

Widows over the age of 60 and living alone were identified using a two-stage process. In the first stage, with the help of the National Health Mission office in Kottayam, widows who fitted the study criteria were identified using the line-list ${ }^{4}$ maintained by ASHAs. Based on this list, areas where there were widows who fulfilled the criteria were shortlisted. This process enabled the identification of Kottayam and Vaikom towns as the urban centres and Manarcaud Parampuzha, Kumarakom and Ayarkunnam as the rural areas for fieldwork. Kottayam and Vaikom were served by secondary-care government hospitals, whereas the rural villages were served either by CHCs (Kumarakom and Ayarkunnam) or a PHC (Manarcaud and Parampuzha). In the second stage, theoretical sampling (Urquhart, 2013) was undertaken, with initial interviews providing new topics that were explored in subsequent interviews. The interview guide and our initial conceptual understanding of the different dimensions of access guided by the theoretical framework of Levesque et al. (2013) were used only as departure points to listen to our participants and think analytically about the data that emerged (Table 1).

As the data collection and analysis occurred concurrently, the topic guide was revised to accommodate new categories that emerged from the initial interviews and analysis (Charmaz, 2014). For example, initial interviews with widows pointed to social networks, the availability of MNREGA work, non-kin support and mental health as key issues. These were explored in detail and also guided the selection of further participants. Following data collection with the widows, FGDs were conducted with ASHAs of each health facility under whose jurisdiction data were collected. All ASHAs who provided health care for widows fulfilling the study criteria were invited to participate. IDIs were held with both medical officers and ASHAs of the health facilities in order to explore in depth some of the issues that had come up during fieldwork.

Twenty-one IDIs were carried out with widows in both urban and rural areas of Kottayam. Eight IDIs and four FGDs were conducted with local health-care providers. Three key informants, including academics and a domain expert on health care for older men and women in south India, were also interviewed (Table 2). Data collection continued until saturation of themes was reached. Seven instances of POs were conducted at the different health facilities, the mobile neighbourhood clinics and at a MNREGA work site. Detailed field notes were recorded and integrated into the analysis.

\section{Data analysis}

With the consent of participants, interviews and FGDs were audio-recorded, transcribed and translated into English, and cross-checked with the original recordings 
Table 1. Initial list of themes explored in the interviews and focus group discussions

\begin{tabular}{|c|c|c|}
\hline $\begin{array}{l}\text { Category of } \\
\text { participant }\end{array}$ & Data collection methods & Initial list of themes \\
\hline Older widows & In-depth interviews & $\begin{array}{l}\text { - Family structure and support systems } \\
\text { - Experience of managing ill-health } \\
\text { - Stages of managing illness/ } \\
\text { requirement for health care } \\
\text { - Experience of seeking formal health } \\
\text { care } \\
\text { - Experience at health facilities } \\
\text { - Facilitators for seeking health care } \\
\text { - Challenges faced in obtaining care } \\
\text { - Experience after obtaining care/ } \\
\text { follow-up }\end{array}$ \\
\hline $\begin{array}{l}\text { Health-care } \\
\text { providers }\end{array}$ & $\begin{array}{l}\text { In-depth interviews and } \\
\text { focus group discussions }\end{array}$ & $\begin{array}{l}\text { - Health needs of older population } \\
\text { - Specific health-care facilities/services } \\
\text { being provided for older population } \\
\text { - Organisation of health-care services } \\
\text { for older population } \\
\text { - Facilitators of health-care provision } \\
\text { - Challenges faced in providing care } \\
\text { - Suggestions to improve access to } \\
\text { health care }\end{array}$ \\
\hline Key informants & In-depth interviews & $\begin{array}{l}\text { - Health needs of the older population } \\
\text { in Kerala } \\
\text { - Broader determinants of health for } \\
\text { the older population } \\
\text { - Policy/state-level programme } \\
\text { initiatives undertaken } \\
\text { - Key challenges in providing health } \\
\text { care } \\
\text { - Suggestions for improving overall } \\
\text { health and wellbeing } \\
\text { - Suggestions for improving access to } \\
\text { health care }\end{array}$ \\
\hline
\end{tabular}

in Malayalam. The translated transcripts were coded using an inductive approach to allow codes and categories to emerge from the data. This involved allowing codes and categories to emerge from the data rather than imposing any external theoretical frameworks on to the data during this process. In the first step open coding was carried out on the initial set of transcripts and field notes, and this led to the emergence of initial themes and categories. Insights received were used to make additions to the interview guide before further interviews were carried out. This process of constant comparison of the data and the various categories that emerged was carried out until no new information was arising out of the interviews (Figure 1). A second author (PU) independently coded a sub-sample of transcripts and the two sets of codes and categories were compared. Any discrepancies in the coding were reviewed through in-depth discussion and negotiated consensus. A 
Table 2. Participants and data collection methods

\begin{tabular}{|c|c|c|c|}
\hline & Rural & Urban & Total \\
\hline Widows & 11 IDIs & 10 IDIs & 21 IDIs \\
\hline Health-care providers: & & & 8 IDIs, 2 FGDs \\
\hline Doctors & $3 \mathrm{IDIs}$ & & \\
\hline Community health workers & & 5 IDIs, 2 FGDs & \\
\hline Key informants: & & & $3 \mathrm{IDIs}$ \\
\hline Academics & 2 IDIs & & \\
\hline Domain expert & & 1 IDI & \\
\hline Participant observation: & & & 8 units \\
\hline Health facilities & 5 units & & \\
\hline MNREGA & 1 unit & & \\
\hline Mobile clinics & & 2 units & \\
\hline
\end{tabular}

Notes: IDIs: in-depth interviews. FGDs: focus group discussions. MNREGA: Mahatma Gandhi National Rural Employment Guarantee Scheme.

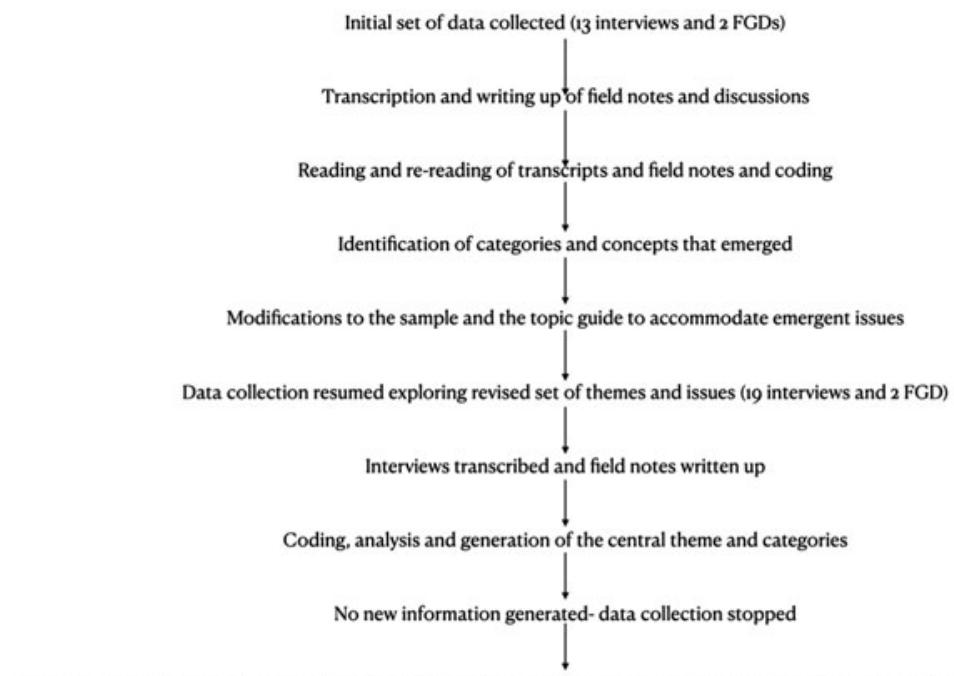

Final analysis including revisiting the aims and objectives of the study and situating the analysed data within the context of the study.

Figure 1. Sampling and analysis process. Note: FGD: focus group discussion.

high level of agreement between coders was noted. Coding of transcripts was carried out using the software package Atlasti.ti 8.4.2.

\section{Establishing rigour and credibility}

Different strategies were used to establish that our findings were credible and reflected the lived reality of our participants. First, we used, member checking 
(Guba and Lincoln, 1994; Forbat and Henderson, 2005; Harvey, 2015), sharing overall findings from the initial analysis with participants and recording their feedback in detailed field notes to validate our findings. These observations were integrated into the findings presented in this paper. Key informants were also emailed a copy of their transcript with the option to discuss both their interview and the overall findings at a mutually agreed time. Secondly, data source triangulation (Patton, 1999) involving the comparison of perspectives of different stakeholders and methodological triangulation (comparing the data that emerged from IDIs, FGDs and POs) were used to enhance the quality of the analyses. Finally, negative case analysis was used to account for outliers in the narrative, helping us to understand why some of our participants had experiences that were contrary to the narrative espoused by others and thus improve the credibility of the findings (Lincoln and Guba, 1985). For example, initial interviews pointed to the general idea that financial status was an enabler of access to health care. However, one participant who was economically independent and lived in her own house pointed out that in spite of financial independence she had very poor social networks and did not find it easy to access health-care services. Exploring the reasons discussed by this outlier led to the discovery that financial independence was not always conducive to building social networks and older widows who had relocated to a new neighbourhood and lived by themselves in particular faced barriers to building their social networks and accessing health-care services in spite of being financially independent.

\section{Ethics approvals}

Informed consent was gained from individual participants prior to data collection. The Human Research Ethics Committees of the University of Canberra and the Indian Institute of Public Health Delhi provided ethical approval. Regulatory permissions were obtained from the Kerala Department of Health as well as the National Health Mission office at Kottayam.

\section{Results}

Widows who took part in this study were from both urban and rural locations in Kottayam district. Their ages ranged from 60 to 77 years, with widowhood duration of 4 months to 37 years. Some widows were in the Above the Poverty Line category (APL) whilst others were categorised as Below the Poverty Line (BPL). APL and BPL are classifications used by all official programmes in India and denote those who are above and below the nationally designated poverty threshold. Common health conditions reported by our participants included hypertension, diabetes, cardio-vascular diseases, osteoporosis, cancer, hearing impairment, poor eyesight as well as age-related conditions including increased frailty and limited mobility. With the exception of two of our participants, the widows, whether belonging to the APL or BPL categories, lived in their own houses. Among the widows who belonged to the APL category, the primary sources of financial support were support from their kin networks, including children, and various government and private pension schemes. Among widows belonging to the BPL category, the primary sources were the widow pension scheme of the state government as well as participation in MNREGA-related work in their area. We present some of the key themes 
and categories (Table 3) that emerged across this varied set of participants and discuss the perspectives of the different stakeholders under each theme.

\section{Altered family structure}

A universal theme that emerged among our participants was how the broader social understanding of what constituted a family unit and the responsibility to care for the old had undergone a fundamental change over time. These included change in living arrangements, from extended family units comprising individuals across generations living in the same house to smaller units that did not necessarily stay together, the migration of the young out of Kerala in search of better jobs and the overall reduction of family size. Widows pointed out how they had taken care of their parents in their old age but were now alone as their children had left Kerala or even India. Many participants described how in previous generations large families were the norm and one child would take up the responsibility of caring for their parents in their old age. However, with the societal shift to smaller families, this tradition of taking on the responsibility for the care of the older members in the family had changed. Yet another change that has come with the transformation of the family unit has been the absence of grandchildren from the daily lives of the older members:

I took care of my mother-in-law. In those days we had to do that. We lived in the same house, so it was easy to do that. Nowadays who lives with their older generation? All that has changed a lot. (IDI, widow, rural, WR 3)

I have a son and a daughter both are not in Kerala so I can't expect them to take care of me. I am alone since the death of my husband. (IDI, widow, urban, WU 2)

Doctors and other key informants who spoke about this also acknowledged that this was the reality and migration would continue in future. The need to reorient services to align with this new reality was recognised:

See this trend is not going to change. It is the case now and it is actually going to increase in the future. Ironically, it is the older men and women who are alone who worked hard to ensure that their children got a good education and jobs. But as a result, they are now alone. (IDI, medical officer, MO 3)

So, the future is looking bad because earlier people died earlier. The life expectancy of Kerala was only 50 years in 1945 . So average life was very low, and you had more children. Now life is high, you have lesser children [sic]. (IDI, key informant, KI 2)

All key informants pointed out that migration has always been a feature of Kerala society, but a more pertinent explanation for the current vulnerability of the older population in Kerala was associated with smaller families becoming the norm:

Migration was always a feature of Kerala society. There used to be more children per family and then one of the children would get the responsibility of taking care of the parents and they would be compensated in some way with more land that is given to them and all of that. But that system has almost crumbled with two children and sometimes one child per family. (IDI, key informant, KI 2) 
Table 3. Key findings that emerged from different participants

\begin{tabular}{|c|c|c|}
\hline Findings & Older widows & Health system \\
\hline $\begin{array}{l}\text { Altered family } \\
\text { structure }\end{array}$ & $\begin{array}{l}\text { - Impact on living arrangements } \\
\text { - Negative impact on support } \\
\text { systems } \\
\text { - Intergenerational connect } \\
\text { weakened }\end{array}$ & $\begin{array}{l}\text { - Accepted the new social reality } \\
\text { - Acknowledged the need to } \\
\text { reorient focus of health } \\
\text { services to cater to the older } \\
\text { population }\end{array}$ \\
\hline Loneliness & $\begin{array}{l}\text { - Related to changed family } \\
\text { structure } \\
\text { - Poor motivation to seek care } \\
\text { - Active involvement in social } \\
\text { activities a preventive measure }\end{array}$ & $\begin{array}{l}\text { - Interpreted loneliness through } \\
\text { lens of medicalisation } \\
\text { - Depression was reported as a } \\
\text { common issue }\end{array}$ \\
\hline $\begin{array}{l}\text { Maintaining } \\
\text { independence }\end{array}$ & $\begin{array}{l}\text { Preferred to stay in their own } \\
\text { homes rather than institutional } \\
\text { arrangements } \\
\text { - Requirement for a person to } \\
\text { accompany to health facility in } \\
\text { case of inpatient care was a } \\
\text { barrier to those living alone }\end{array}$ & $\begin{array}{l}\text { - Agreed that the older } \\
\text { population prefers their } \\
\text { independence } \\
\text { - Independent living feasible } \\
\text { only until mobility is not an } \\
\text { issue for the older population }\end{array}$ \\
\hline Social networks & $\begin{array}{l}\text { - Quality and presence of social } \\
\text { networks strongly predicted } \\
\text { wellbeing and access to health } \\
\text { care } \\
\text { - Social networks more important } \\
\text { than financial status } \\
\text { - Ability to form social networks } \\
\text { decreased with age } \\
\text { - Non-kin networks were more } \\
\text { relevant than kin networks }\end{array}$ & $\begin{array}{l}\text { - Community health workers } \\
\text { pointed out that social } \\
\text { networks were a strong } \\
\text { indicator of wellbeing and } \\
\text { ability to access resources } \\
\text { - Economically poor older } \\
\text { widows fared better in building } \\
\text { social networks than the rich }\end{array}$ \\
\hline $\begin{array}{l}\text { Neighbourhood } \\
\text { clinics }\end{array}$ & $\begin{array}{l}\text { - Provided decentralised care } \\
\text { - Strengthened social networks } \\
\text { - Welcomed by community } \\
\text { - Limited to urban areas }\end{array}$ & $\begin{array}{l}\text { - PHCS in rural areas dependent } \\
\text { on NCD clinics } \\
\text { - Older population expected to } \\
\text { gather at PHC }\end{array}$ \\
\hline $\begin{array}{l}\text { Challenges of } \\
\text { urban living }\end{array}$ & $\begin{array}{l}\text { - Isolated living conditions } \\
\text { - Greater reliance on private } \\
\text { health-care facilities } \\
\text { - Poor social networks when } \\
\text { compared with rural } \\
\text { counterparts }\end{array}$ & $\begin{array}{l}\text { - Challenge to access residences } \\
\text { of older widows } \\
\text { - No system ( panchayat) as in } \\
\text { rural areas to obtain data on } \\
\text { the older population in urban } \\
\text { areas }\end{array}$ \\
\hline $\begin{array}{l}\text { Limitations of } \\
\text { health insurance }\end{array}$ & $\begin{array}{l}\text { - Health insurance did not address } \\
\text { most common requirements for } \\
\text { health care } \\
\text { - Was useful in case of inpatient } \\
\text { admission }\end{array}$ & $\begin{array}{l}\text { - Agreed that prominent health } \\
\text { insurance schemes did not } \\
\text { address conditions relevant to } \\
\text { the older population } \\
\text { - Useful to have coverage in case } \\
\text { of catastrophic health } \\
\text { expenditure }\end{array}$ \\
\hline
\end{tabular}

Notes: NCD: non-communicable disease. PHC: Primary Health Centre. 


\section{Loneliness}

Loneliness and an overall lack of meaning was mentioned by the majority of the widows. The altered family structure coupled with migration of the young meant that most older widows lived by themselves and did not have caring responsibilities for their grandchildren as in the past. This shift is a recent development in Kerala society and deprived older widows of both the presence of family members within their home and caring responsibilities that gave them a new sense of purpose. Those who reported feeling lonely also discussed their lack of motivation to seek health-care services until their condition deteriorated to the point of them being unable to manage activities of daily living. Among widows who reported loneliness, belief in God was a source of comfort and this was reported across religious affiliations of our participants:

For the past 30 years, I have been living alone here. I do not have anyone, and I am weak due to my age. When I think of it, I feel sad. I have nobody to even accompany me to a hospital. (IDI, widow, urban, WU 1)

I have been here for four years. I have nobody to talk with. I watch TV for some time, but after seeing it for some time I get bored. Then I sit here by doing nothing. If we do anything, even lightly then we get mental happiness. How can we watch TV for all time? (IDI, widow, rural, WR 6)

Doctors who were interviewed spoke about the sense of loneliness and being left behind as widely prevalent among the older population. However, they discussed what was essentially a result of multiple social changes including family structures that changed, caring responsibilities that were altered, etc., from a medical perspective that required clinical interventions to be addressed. While there was an overall acknowledgement of this issue, there were no serious efforts to address even the issue of depression from a clinical perspective and provide mental health services. Most health-care services for older adults in Kerala focused either on chronic disease management or palliative care. Services for individuals with health conditions that did not fit into these two broad categories (such as mental illness, for example) were lacking:

Depression is the main problem for most of them. That itself is the reason for enhancing the severity of their illnesses. If we can tackle it while they come to us ... they actually come to talk with us for five minutes. (IDI, medical officer, MO 1)

Mental health is completely neglected. There is something known on paper known as a district mental health programme. I don't think anything is happening with that. I don't think there is a sensitivity towards the fact that you know the older population has mental health needs and it needs to be delivered in a sensitive manner to them. (IDI, key informant, KI 1)

Among our sample, a small section of the widows did not report loneliness as an issue. A common feature of this sub-group was participation in social activities. For example, one of the widows living in an urban area spoke about how she took an 
active part in her church committees. This ensured that she was able to contribute to others and also forget about living alone without her children. Another widow spoke of how her neighbours kept her busy and enquired about her. One of her key daily activities was watching her neighbour's grandchild play in her courtyard when she returned from school:

No, I won't say that I am lonely. The reason is that I keep myself busy with activities at my church and I also take tuitions. I am not sitting at home all the time and there is a big difference. If you come across widows in your work who are lonely or sad, ask them about their activities. I feel it is only those who are not engaged in any activity who are depressed and feeling lonely. (IDI, widow, urban, WU 6)

\section{Maintaining independence}

Several of the widows in our sample expressed a strong desire to be independent. To them living in their own homes as opposed to institutional care homes, even if this meant that they had challenges when it came to accessing health care, gave them more power and control over their lives which was important for them. Even those who suffered from limited mobility preferred to remain living in their own home. This was in contrast to the understanding expressed by some of the health system stakeholders that institutional care might be a valuable option for those living alone, especially if they were suffering from conditions that restricted their mobility or required constant care. One of the widows whose mobility was highly restricted stated that she preferred to live out the remaining time in her own home which was associated with a lot of memories for her. However, at the same time there was an acknowledgement that if she became bedridden for any reason, she would have to shift to a care home for older adults as it would be impractical to continue living alone.

Linked to this need for independence was the desire not to be a burden to others, including children, relatives or neighbours. Referrals and inpatient health care required someone to accompany the person receiving the treatment; many of our participants postponed seeking care until their symptoms were no longer bearable to avoid having to impose this on others. While exploring this further, some of the widows explained that at their age enduring pain and discomfort was a part and parcel of life. Doing so was seen as the right thing to do, rather than constantly disturbing others for help to access health-care services:

My daughters are living with their family in another place. Even though they have a job they have their own difficulties. So, I am not ready to make them worry about me also. (IDI, widow, rural, WR 9)

No, I do not go at the start. I go when I feel that it is intolerable. (IDI, widow, rural, WR 4)

\section{Social networks}

Among our participants, two types of networks emerged that were important when it came to their health and access to health care. These were kin networks 
comprising immediate family such as children, grandchildren or relatives who lived nearby and non-kin networks that consisted of neighbours and larger social groups to which a widow was connected. These groups included membership of a religious congregation, social gatherings in the neighbourhood, as well as MNREGA work settings and neighbourhood clinics. A common feature noted was how participants formed a 'personal community' that included kin and non-kin relationships depending on their particular circumstances, preferences and values. It was this 'personal community' that the widows depended on when in need. The quality of relationships that a widow had with those who were part of this sub-group strongly predicted their ability to access multiple resources including health care. For example, several of the widows in our sample did not have any strong kin networks, but they were able to access health care when required due to their strong non-kin networks:

I cannot go out alone in my condition, so my neighbour he will call an auto and take me and then bring me back here. He even used to get me my rations from the store till they started the new rule of verifying my thumb impression.

(IDI, widows rural, WR 5)

In fact, the quality and presence of strong social networks were mentioned by different stakeholders as key factors that promoted health and wellbeing, in general, and access to resources, in particular:

It is not financial status when you talk of the situation of widows living alone, it is mainly the relationships they have with their neighbours and others that matter. We have seen many widows who are well to do but they are lonely and depressed and if something happens to them no one will even come to know in time. (FGD, community health workers, FGD 2)

Social networks played a positive role with regard to health and wellbeing in two prominent ways. First of all, those in our sample who had good kin or non-kin relationships spoke more about their motivation to remain healthy and were less likely to refer repeatedly to loneliness during the interviews. Secondly, the presence of strong social networks enabled greater access to resources including health care. With regards to health care, this included aiding physical access to health facilities and doctors by facilitating transport and accompanying a widow to the health facility. There was also a sense of solidarity among the community when it came to support for older widows in their locality. For example, during fieldwork in certain areas, it was observed that shopkeepers allowed widows, who were very poor and solely dependent on widow pension or other government support, to obtain provisions from their stores and run up debts until they received the pension payment. Yet another instance was how local representatives allowed women who were older and unable to do much physical work to register for MNREGA work while looking the other way when these women were unable to contribute. When this was explored, the local representative explained that the circumstances of some of the women was really difficult and so the community was ensuring that they were able to get some monetary support. Some of our participants also pointed out how ASHAs who visited them helped 
them to identify relevant government schemes, informed them about amenities that were available for them at the local health facility and enrolled them into government schemes designed to support the older population. Yet another important aspect that was highlighted was how the home visit by the ASHA provided an opportunity to talk about their problems. ASHAs in many areas were therefore an important part of the community networks for some of our participants:

One ASHA came here to see me. She asked me whether I need a walker. I said no. But I am so happy that she asked me so. (IDI, widow, rural, WR 8)

We also observed that in certain instances, solidarity amongst widows trumped considerations of caste or religion:

The person you met on the way to my house, she is a nair woman while I am an ezhava. Till my house was built by the government recently, I used to go and sleep at her place. We have so many things in common. Our caste did not matter at all. Even now we are good friends. (IDI, widow, rural, WR 11)

Many of the ASHAs, as well as our key informants, noted that widows who were financially well off were less able to depend on social networks compared to those who were poor. One key informant who had several years of experience working among the older population in Kerala explained that poor families tended to depend more on their local community and hence a strong set of non-kin networks was already in place by the time a person reached 60 years of age. Thus, being financially poor was in this situation not necessarily a negative feature, since it was a potential enabler of social networks:

Women in the BPL category living alone have the possibility of having more social networks. They depend more on others in the community. They need networks far more, support far more. Because by being BPL itself they are socially dependent. So, they have more links and communication with many people. In a place if the houses are small and situated nearby then there is greater chance of interaction between the neighbours; mutual support comes automatically. (IDI, key informant, KI 1)

However, the ability to build and nurture new social networks diminishes with age. In our sample, we had three widows who had recently moved to their present localities and found it difficult to integrate with their local community. They chose to depend on their kin networks even if these were located far away. The mutually trusting and supportive relationships with the local community observed for other widows was absent for these three widows. Widows might also lack these social networks if they were stigmatised and excluded from the community for various reasons, including mental illness or being 'tainted' as immoral:

At the same time for those who have been excluded from the community because of any reason may get opposition from the society. For example, if a widow is classified as a 'bad woman' by her community then it becomes very difficult. They will exclude her and not support her. (IDI, key informant, KI 1) 


\section{Challenges of urban living}

During fieldwork, it was observed that reaching widows with services and enrolling them in various government schemes was comparatively easier in rural areas compared to the urban centre in Kottayam. Kerala has an established tradition of local self-governance through the panchayat raj system in the rural areas. The panchayat raj is a system of local self-governance that is prevalent in India and is the lowest tier of governance in rural areas. Due to their nature of being decentralised, panchayats were more aware of the number of older adults living in the areas under their jurisdiction and this enabled ASHAs and other community workers to reach out to the widows in an efficient manner. The situation was very different in urban centres where the older adults preferred not to interact much with the public health system or other civic officials. ASHAs in urban centres also found it challenging to reach the older population, especially those who were financially well off and lived in apartments. This was partly due to the socially isolated nature of these living conditions and the minimal interaction with the local community:

At least in the rural area we have a system in place and people know their neighbours. In urban centres we have a problem in reaching those in need of us. Add to this those who are living in apartments where they do not know who is living next to them. We also do not have the data that we have in the rural areas on the elderly population. (IDI, key informant, KI I)

One of the main issues in the urban areas is reaching the older population, only if our ASHA is able to reach those in need can we offer services right? Even physically getting access to these buildings for our ASHAs is difficult due to the security measures that are usually common at these apartments. (IDI, medical officer, MO 2)

During fieldwork we also realised that in some cases neighbours were not very aware of older adults who lived by themselves in some of these apartments. Additionally, some of the ASHAs reported how it was challenging to visit those living in urban areas when compared to those living in the villages as physical access to an urban apartment was restricted due to various security features that were in place in most apartments. Key informants and health-care workers described this as a difficult situation. Reaching widows who did not have adequate support systems was tougher for the public health system than providing services in rural areas.

Some of the urban participants described how their primary support system centred around personal kin networks, preferring not to interact with others from the local community. While it is possible that some of these widows had strong kin networks that provided support, it also highlighted the challenges a widow without strong kin networks living in an urban centre could face when the need arose to access health care. One of our key informants spoke of how several factors made it challenging for the public health system to reach out to older widows in urban areas. They included a general trend of relying on private healthcare providers among the rich, as well as the tendency to rely on their own self and immediate family rather than the community for their needs, which was reinforced by the individualistic nature of urban living. 


\section{Neighbourhood clinics that enabled access}

Vayomitram neighbourhood clinics emerged as an important facilitator of access to health care, particularly in urban areas. These mobile clinics visited localities where a large number of older people above the age of 65 were living and provided preventive and curative primary care. Clinics functioned out of government day-care centres (anganwadis) and other schools in the area. Older people from both APL and BPL populations made use of these clinics in order to get primary care and treatment for their chronic conditions. What stood out was how these clinics transformed from providing health care to enabling strong social networks among the attendees. While participants mentioned the advantages of decentralised care, what motivated them to attend was the fact that the neighbourhood clinics went beyond merely providing health-care services. Participants recalled celebrating birthdays and festivals at the clinics and also discussed how the staff engaged with them outside diagnosis and prognosis of their health conditions:

We celebrate all major festivals and even birthdays sometimes at the clinic. It is more like a club of old people than a clinic. (IDI, widow, urban, WU 10)

This approach to providing health care for older populations was not observed in rural areas where most of the care was delivered at the PHC level during the weekly 'NCD clinics'. As a result, older men and women with any NCD conditions gathered at the PHC on this day, resulting in long queues. Doctors described this as counterproductive, since it meant that the quality of care suffered in the process:

You saw the queues right; it is not easy to provide good quality care for everyone when you have such long queues. Every one of them expects me to talk to them for at least five minutes and if I don't engage them in conversation then they are not happy. (IDI, medical officer, MO 2)

\section{Limitations of health insurance}

With the exception of two of the widows, our participants were covered under either public or private health insurance schemes. Most of those who were BPL were covered by government insurance schemes whereas those who were APL had subscribed to private insurance. Except for one of our participants, who made use of insurance for inpatient cancer treatment, none of the participants had made use of the insurance schemes. It was illuminating that of the two who did not have any insurance, one widow had let her government health insurance lapse. She explained that being covered by health insurance did not address her common health-care expenses and hence she did not find any reason to renew it even though it was provided to her for free! When this issue was explored with other participants, they concurred that for most of their health-care expenditure (which required outpatient primary care), their health insurance provided no cover:

I had it for two years and after that I did not renew it and I will not renew it. What is the use of having this card in my bag when I am spending from my pocket to buy my medicines? (IDI, widow, rural, WR 5) 
I have government health insurance. They told to take it and I took it. It was very useful when I had to get chemotherapy for cancer. (IDI, widow, rural, WR 9)

\section{Discussion}

The ageing of the global population has significant implications, especially for health and social policy and services. Ensuring access to health care for older populations is a key component that will determine whether or not UHC and the Sustainable Development Goals are achieved (Barber and Rosenberg, 2017). Among the older population, widows living alone are a highly vulnerable group and previous work in the Indian context has shown that while morbidity patterns and the requirement for health care are high among older widows, the utilisation of health-care services by them is poor (Chen and Dreze, 1992; Agrawal and Keshri, 2014; Perkins et al., 2016). Age, location, education and various socio-economic factors have been shown to have an impact on access to health care for older widows in India (Agrawal and Keshri, 2014). Our work, while acknowledging that such factors might have implications for health and access to services, shows that social networks and the social capital that they confer play a significant role in promoting both wellbeing and better access to health care. These networks were present at three levels: family, neighbourhood and the wider community. Participants formed a 'personal community' drawn from these three levels but characterised more by non-kin relationships. The quality of relationships in these 'personal communities' was far more important in promoting access to health care than other socio-economic factors. Connections with neighbours and local communities have been shown to be very important in promoting wellbeing among older women (Tuohy and Cooney, 2019). We found this to be true in our study as well. Strong social networks also addressed the loneliness that was common among the widows. Social support and having a sense of belonging to a common group has also been shown to improve healing and overall wellbeing in certain chronic conditions for the old (Upton et al., 2015). However, variability in forming these networks was observed. Those who had settled in a neighbourhood in their twilight years, individuals stigmatised by their local community and economically well-to-do older widows living in urban towns were less likely to form strong personal communities in their neighbourhood.

Economic status is universally considered an important predictor of vulnerability. However, our study shows how poor older widows were able to develop strong social networks when compared with those who were financially well off. One reason for this included a history of dependence on the local community that enabled more communication and interconnectedness. This is an important issue that needs to be taken into account when government initiatives seek to provide services for the older population, especially in health care.

The role of the family as a key source of support and interdependence for older people has been demonstrated by several studies (Desai et al., 2010; Brijnath, 2012; Navaneetham and Dharmalingam, 2012). However, we found that declining fertility and high levels of migration by the younger population had changed the role of the family in the care and support for older adults in Kerala. This had an impact not only on sources of support for elderly people, but also changed the reciprocal 
Table 4. Programmes to improve health care for the older population

\begin{tabular}{ll}
\hline Vayomitram & $\begin{array}{l}\text { Neighbourhood clinics in urban areas for those above } 65 \text { providing } \\
\text { primary health care for chronic diseases }\end{array}$ \\
\hline NCD clinics & $\begin{array}{l}\text { PHC-based clinics for providing primary care and medicines including } \\
\text { insulin for persons with NCDs }\end{array}$ \\
$\begin{array}{l}\text { Palliative care } \\
\text { programme }\end{array}$ & $\begin{array}{l}\text { Nursing and primary care for bedridden patients at their home provided } \\
\text { by a special palliative care team working under the PHC with support } \\
\text { from the local self-government. Secondary- and tertiary-level care } \\
\text { including physiotherapy is provided by units under the National Health } \\
\text { Mission }\end{array}$ \\
Panjarakootam & $\begin{array}{l}\text { Local groups of older men and women formed in connection with } \\
\text { anganwadis (child-care centres) for recreational activities and linking up } \\
\text { with children in the neighbourhood }\end{array}$ \\
\hline
\end{tabular}

Notes: NCD: non-communicable disease. PHC: Primary Health Centre.

relationships that existed between older adults and the young in extended families in the past. Older adults were denied opportunities to be involved with their grandchildren, depriving them of relationships that have been shown to be an important component of productive ageing in India (Visaria and Dommaraju, 2019). Widows who participated in our study referred to this development with a sense of loss and inevitability.

One of our findings was the significant role played by neighbourhood clinics in improving access to health care and building social capital for older men and women in the areas in which they functioned. A key factor to explain this finding was that these clinics did not limit themselves to dispensing clinical advice, primary care and medicines. An important function of the neighbourhood clinics was that they addressed the social and psychological needs of the older population by providing a place for them to gather and build their social networks. This in turn enabled better wellbeing and access to resources long after the mobile clinic left the neighbourhood. Evidence from other settings shows that integrating clinical care with socialisation and peer support leads to better health outcomes among the old (Edwards et al., 2009). Neighbourhood clinics also demonstrated that most of the health-care needs for our sample were primary health-care based. This has been shown by other studies that have indicated a need for a reorientation towards routine primary health care, rather than specialised health technology-intensive approaches (Barber and Rosenberg, 2017).

Given the proportion of the older population in Kerala, the state has initiated several programmes to address their health-care needs (Table 4). However, most interventions focus on NCD such as diabetes, hypertension and cardio-vascular diseases, and have converged in the form of the NCD clinic delivered through various health facilities. Palliative care for those who are sick and bedridden is also being implemented across the state albeit in a limited manner. However, a crucial issue that is omitted and has important ramifications for the wellbeing of older people is mental health. Loneliness, depression and psychological distress among older adults and its impact on their wellbeing is well-established (Taylor et al., 2016). Loneliness and concerns about the future was a common issue that emerged in our study. While relationships with neighbours and the community did support 
Table 5. Recommendations for policy and programmes

Policy:

1. Develop a comprehensive social protection policy that incentivises the formation of social networks and other initiatives that build social capital among the older population

2. Decentralise delivery of health services including diagnostic support up to the sub-centre level in rural areas and neighbourhoods (wards) in urban areas

3. Review the utility of the present models of health insurance and look at alternative models of financial protection for the older population based on their health-care requirements

4. Invest in providing comprehensive primary health care to address the health-care needs of elderly people

5. Adopt an intersectoral approach to address the underlying issues of the isolation of elderly widows

Programmes:

1. Train and sensitise ASHAs and medical officers in the provision of culturally sensitive geriatric care and support

2. Work with social organisations, local clubs, faith-based groups and other voluntary agencies to reach out to isolated older widows in urban areas

3. Address the need for culturally sensitive mental health and counselling services for elderly widows

Note: ASHAs: accredited social health activists.

wellbeing to a large extent, some of our participants found the cultural changes to the family unit distressing, and this clearly had an impact on their mental health and wellbeing. Addressing this requires health systems to move beyond medicalising the issue as they currently do. Depression and anxiety in older populations are often symptoms of loneliness, with lack of social networks being the root cause of these mental health problems. Providing mental health or wellbeing services that are sensitive to the cultural aspect of this phenomenon, including promoting the development of social networks in neighbourhoods, would provide a more fundamental solution to this problem.

A key intervention under UHC schemes globally and in India has been the provision of health insurance that addresses direct costs associated with accessing health care at the point of service delivery (Giedion et al., 2013). While the vast majority of our study participants were covered by either public or private health insurance, it was irrelevant to most of their health-care requirements. This was because health insurance did not cover outpatient primary care or the cost of medication if it had to be purchased. Therefore, while being covered by health insurance, widows continued to pay from their pockets for most of their health-care expenditure. This gap emphasises the need to reconsider whether the present form of health insurance is relevant to the needs of the majority of the older population. Failure to address this issue means the ability to obtain health insurance has no meaningful impact on the widow's ability to access health-care services.

Ageing and the increasing numbers of women who live alone in their twilight years is a new demographic phenomenon in India. The global commitment to ensuring UHC provides an opportunity to ensure that older communities and, in particular, the vulnerable among them such as widows are able to access health care when they require it and remain active members of their communities. This study provides evidence that merely ensuring the availability of health insurance 
coverage, health-care facilities or medicalising underlying social issues will not ensure UHC. UHC interventions for older populations need to consider the cultural and social contexts of the community and include interventions that promote social capital, prevent social isolation and build local communities. For this to occur, several areas including social and health policy as well as health-care programmes being implemented need to be revisited (Table 5) in the context of the emerging situation of older communities in Kerala.

\section{Limitations}

Our study has obvious limitations. The local context and, in particular, the local self-governance unit of the panchayat has a strong influence on the initiatives that are implemented for older widows living under their jurisdiction. A second limitation is the fact that this study has been carried out in Kerala, a highly literate state in India with good public health infrastructure and highly decentralised local self-governance mechanisms. This might not be the case with many other states in India. A final limitation is the fact that our sample is limited to older widows and leaves out widowers. Hence the study might not reflect some issues that would have been pertinent to older widowers and their access to health care. Despite these contextual limitations, we believe that our work sheds valuable insight on mechanisms that promote wellbeing and access to health care for older widows.

Acknowledgements. We sincerely thank all the participants of our study: the widows who participated in our study, doctors, other health-care workers in Kottayam district and the key informants who shared their experiences with us. Many thanks to the Department of Health, Government of Kerala for granting the requisite permissions to carry out this research and to the National Health Mission office at Kottayam for the support provided. A special word of thanks goes to Jessy the ASHA Coordinator of Kottayam and Sr Valsala of Vaikom Taluk Hospital for their role in facilitating data collection. We are very grateful to all the ASHAs who accompanied the lead author and facilitated data collection.

Author contributions. MSG carried out the data collection and drafted the manuscript with contributions from RD, IM, RG, VS and PU. MSG and PU were involved in the analysis of the qualitative data. All authors read and approved the final manuscript.

Financial support. This work was carried as part of the PhD research of MSG. Field work was supported through a grant available to all $\mathrm{PhD}$ candidates towards project expenses at the University of Canberra.

Conflict of interest. MSG, PU, RD, IM and RG declare that they have no conflicts of interest. VS is the district programme manager at the National Health Mission office at Kottayam where fieldwork was carried out. His role was limited to contributing to the drafting of this manuscript.

Ethical standards. The Human Research Ethics Committees of the University of Canberra (20180074) and the Indian Institute of Public Health Delhi (IIPHD_IEC_03_2018) provided ethical approval for this study. Regulatory permissions were obtained from the Kerala Department of Health (GO(Rt) No2677/2018/H\&FWD). All participants gave informed consent prior to data collection.

\section{Notes}

1 A taluk is an administrative sub-division of a district in India comparable to a township or a borough in Western societies.

2 A sub-centre is established in a plain area with a population of 5,000 people and in hilly/ difficult-to-reach/tribal areas with a population of 3,000, and it is the most peripheral and first contact point between the public health-care system and the community. 
3 The MNREGA is a national programme that guarantees work at minimum assured wages.

4 As part of the Government of Kerala's efforts to reach out to the older populations, panchayats mapped all the older men and women living alone in their jurisdiction. This list was available within the Department of Health and was used to reach out to older men and women and provide them with services.

\section{References}

Acharya SS (2018) Health equity in India: an examination through the lens of social exclusion. Journal of Social Inclusion Studies 4, 104-130.

Agrawal G and Keshri K (2014) Morbidity patterns and health care seeking behavior among older widows in India. PLOS ONE 9, e94295.

Alam M and Karan A (2010) Elderly health in India: dimensions, differentials and over time changes. In Giridhar G, Meijer F, Alam M, James KS, Sathyanarayana KM and Kumar S (eds). Building a Knowledge Base on Ageing in India: A Series of Programmatic and Research Studies. New Delhi: United Nations Population Fund, pp. 1-31.

Barber SL and Rosenberg M (2017) Aging and universal health coverage: implications for the Asia Pacific region. Health Systems \& Reform 3, 154-158.

Basu S and King AC (2013) Disability and chronic disease among older adults in India: detecting vulnerable populations through the WHO SAGE Study. American Journal of Epidemiology 178, 1620-1628.

Brijnath B (2012) Why does institutionalised care not appeal to Indian families? Legislative and social answers from urban India. Ageing \& Society 32, 697-717.

Byles J, Dobson A, Pachana N, Tooth L, Loxton D, Bereecki J, Hockey R, McLaughlin D and Powers J (2019) Women, Health and Ageing: Findings from the Australian Longitudinal Study on Women's Health. Canberra: Australian Department of Health and Ageing.

Charmaz K (2014) Constructing Grounded Theory. London: Sage.

Chen M (1998) Widows in India: Social Neglect and Public Action. New Delhi: Sage.

Chen M and Dreze J (1992) Widows and health in rural North India. Economic and Political Weekly 27, $81-82$.

Chokshi M, Patil B, Khanna R, Neogi SB, Sharma J, Paul VK and Zodpey S (2016) Health systems in India. Journal of Perinatology 36, S9-S12.

Crawley M (2008) The Way We Are, Facts About Older Women in Ireland in 2008. Dublin: Older Women's Network.

Davidson PM, Digiacomo M and McGrath SJ (2011) The feminization of aging: how will this impact on health outcomes and services? Health Care for Women International 32, 1031-1045.

Desai S, Dubey A, Joshi BL, Sen M, Shariff A and Vanneman R (2010) Human Development in India: Challenges for a Society in Transition. New Delhi: Oxford University Press.

DiGiacomo M, Lewis J, Nolan MT, Phillips J and Davidson PM (2013) Health transitions in recently widowed older women: a mixed methods study. BMC Health Services Research 13, 143.

District Administration Kottayam (2020a) Administrative Setup. Kottayam: National Informatic Centre.

District Administration Kottayam (2020b) Hospitals. Kottayam: National Informatic Centre.

Dreze J (1990) Widows in Rural India. London: Development Economics Research Programme.

Edwards H, Courtney M, Finlayson K, Shuter P and Lindsay E (2009) A randomised controlled trial of a community nursing intervention: improved quality of life and healing for clients with chronic leg ulcers. Journal of Clinical Nursing 18, 1541-1549.

Forbat $\mathbf{L}$ and Henderson J (2005) Theoretical and practical reflections on sharing transcripts with participants. Qualitative Health Research 15, 1114-1128.

Giedion U, Alfonso EA and Diaz Y (2013) The Impact of Universal Coverage Schemes in the Developing World: A Review of the Existing Evidence. Washington, DC: The World Bank.

Guba E and Lincoln Y (1994) Competing paradigms in qualitative research. In Denzin N and Lincoln Y (eds). Handbook of Qualitative Research. London: Sage, pp. 105-117.

Harvey L (2015) Beyond member-checking: a dialogic approach to the research interview. International Journal of Research \& Method in Education 38, 23-38.

Hurst G, Wilson P and Dickinson A (2013) Older people: how do they find out about their health? A pilot study. British Journal of Community Nursing 18, 34-39. 
Kerala Social Security Mission (2018) Vayomithram. Thiruvananthapuram, India: Social Justice Department.

Kurian R (1979) Patterns of emigration from Kerala. Social Scientist 7, 32-53.

Levesque J-F, Harris MF and Russell G (2013) Patient-centred access to health care: conceptualising access at the interface of health systems and populations. International Journal for Equity in Health 12, 18.

Lincoln YS and Guba GE (1985) Naturalistic Inquiry. Newbury Park, CA: Sage.

Navaneetham K and Dharmalingam A (2012) A review of age structural transition and demographic dividend in South Asia: opportunities and challenges. Journal of Population Ageing 5, 281-298.

Ní Léime Á, Duvvury N and Callan A (2015) Pension provision, gender, ageing and work in Ireland. In Walsh K, Carbney GM and Ní Léime A (eds), Ageing Through Austerity: Critical Perspectives from Ireland. Bristol, UK: Policy Press, pp. 63-78.

Patton MQ (1999) Enhancing the quality and credibility of qualitative analysis. Health Services Research 34, 1189-1208.

Perkins JM, Lee HY, James KS, Oh J, Krishna A, Heo J, Lee JK and Subramanian SV (2016) Marital status, widowhood duration, gender and health outcomes: a cross-sectional study among older adults in India. BMC Public Health 16, 1032.

Registrar General \& Census Commissioner of India (2011) Census of India. Census Provisional Population Totals. New Delhi: Office of the Registrar General \& Census Commissioner of India.

Registrar General of India (2001) Census of India 2001: Kerala Data Highlights, The Scheduled Tribes. New Delhi: Office of the Registrar General of India.

Registrar General of India (2017) Sample Registration System: Statistical Report 2017. New Delhi: Office of the Registrar General \& Census Commissioner of India.

Roy K and Chaudhuri A (2008) Influence of socioeconomic status, wealth and financial empowerment on gender differences in health and healthcare utilization in later life: evidence from India. Social Science Medicine 66, 1951-1962.

Samanta T, Chen FN and Vanneman R (2015) Living arrangements and health of older adults in India. Journals of Gerontology: Psychological Sciences and Social Sciences 70B, 937-947.

Song M and Kong E-H (2015) Older adults' definitions of health: a metasynthesis. International Journal of Nursing Studies 52, 1097-1106.

Sreerupa and Rajan SI (2010) Gender and widowhood: disparity in health status and health care utilization among the aged in India. Journal of Ethnic \& Cultural Diversity in Social Work 19, 287-304.

State Planning Board (2019) Economic Review. Thiruvananthapuram, India: Government of Kerala.

Sudha S, Suchindran C, Mutran EJ, Rajan SI and Sarma PS (2006) Marital status, family ties, and selfrated health among elders in South India. Journal of Cross-cultural Gerontology 21, 103-120.

Taket A, Crisp BR, Nevill A, Lamaro G, Graham M and Godfrey SB (eds) (2009) Theorising Social Exclusion. New York, NY: Routledge.

Taylor HO, Taylor RJ, Nguyen AW and Chatters L (2016) Social isolation, depression, and psychological distress among older adults. Journal of Aging and Health 30, 229-246.

Tuohy D and Cooney A (2019) Older women's experiences of aging and health: an interpretive phenomenological study. Gerontology and Geriatric Medicine 5, 2333721419834308.

United Nations (2015) World Population Aging 2015. New York, NY: Department of Economic and Social Affairs, Population Divison.

United Nations (2019) World Population Ageing 2019: Highlights. New York, NY: Department of Economic and Social Affairs, Population Division.

Upton D, Upton P and Alexander R (2015) Contribution of the Leg Club model of care to the well-being of people living with chronic wounds. Journal of Wound Care 24, 397-405.

Urquhart C (2013) Grounded Theory for Qualitative Research. London: Sage.

Verbrugge LM (1985) Gender and health: an update on hypotheses and evidence. Journal of Health and Socical Behaviour 26, 156-182.

Visaria P (2001) Demographics of ageing in India. Economic and Political Weekly 36, 1967-1975.

Visaria A and Dommaraju P (2019) Productive aging in India. Social Science \& Medicine 229, 14-21.

Vlassoff C (1994) Gender inequalities in health in the Third World: uncharted ground. Social Science and Medicine 39, 1249-1259.

World Health Organization (WHO) (1978) Primary Health Care: Report of the International Conference on Primary Health Care Alma Ata, USSR, 6-12 September 1978. Geneva: WHO. 
World Health Organization (WHO) (2005a) The Commission on Social Determinants of Health - What, Why and How? Geneva: WHO.

World Health Organization (WHO) (2005b) Fifty-eighth World Health Assembly: Resolutions and Decisions. Geneva: WHO.

World Health Organization (WHO) (2007) Women, Ageing and Health: A Framework for Action. Geneva: WHO.

World Health Organization (WHO) (2020) Thirteenth General Programme of Work: Measures for Impact Assessment. Geneva: WHO.

Cite this article: George MS, Gaitonde R, Davey R, Sukumaran V, Mohanty I, Upton P (2023). Social networks and their impact on access to health care: insights from older widows living alone in Kottayam, South India. Ageing \& Society 43, 1141-1163. https://doi.org/10.1017/S0144686X21001100 